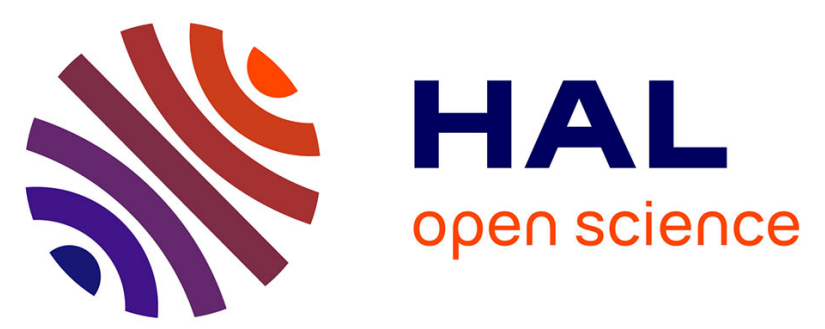

\title{
From the French Citizens' Convention on Climate to the Conference on the Future of Europe: A participatory science and democracy perspective
}

\author{
Laurence Eymard
}

\section{- To cite this version:}

Laurence Eymard. From the French Citizens' Convention on Climate to the Conference on the Future of Europe: A participatory science and democracy perspective. European Law Journal, 2020, 26 (1-2), pp.136-140. 10.1111/eulj.12369 . insu-03029398

\section{HAL Id: insu-03029398 \\ https://hal-insu.archives-ouvertes.fr/insu-03029398}

Submitted on 28 Nov 2020

HAL is a multi-disciplinary open access archive for the deposit and dissemination of scientific research documents, whether they are published or not. The documents may come from teaching and research institutions in France or abroad, or from public or private research centers.
L'archive ouverte pluridisciplinaire HAL, est destinée au dépôt et à la diffusion de documents scientifiques de niveau recherche, publiés ou non, émanant des établissements d'enseignement et de recherche français ou étrangers, des laboratoires publics ou privés. 


\title{
From the French Citizens' Convention on Climate to the Conference on the Future of Europe: a participatory science and democracy perspective
}

\author{
Laurence Eymard* \\ * Emeritus Research Director at the French National Centre for Scientific Research (CNRS); Co-founder of the Sorbonne \\ University Institute for Environmental Transition (SU-ITE)
}

\begin{abstract}
The Citizens' Convention on Climate (CCC) gathered 150 people, randomly selected but representing the diversity of the French society. Its mandate was to formulate a series of concrete measures aimed to achieve at least a 40\% reduction of greenhouse gas emissions by 2030 (compared to 1990) while preserving social justice. The citizens auditioned experts on various topics from climate to economics and then formulated their own proposals, thus building an effective consensus, beyond individual specific interests. Moreover, proposals formed a coherent whole, and in this regard fare much better than previous attempts to tackle environmental and climate transition through public debates. This methodology shows how citizen science can produce efficient and quality outcomes. This opens new perspectives for democracy on the basis of new interaction channels between law-makers, professional experts and citizens. This seems to be the approach chosen for the Conference on the Future of Europe as well. Gathering citizens from all EU countries to work on important topics for Europe and Europeans could be a way to build a common vision, and contribute to the creation of a true European common good. Citizens' direct involvement in science and democracy might be one of the keys to meaningfully and thus successfully address their shortcomings.
\end{abstract}

\section{Introduction}

In the Autumn of 2019, after several months of weekly 'yellow vest' protests, the Citizens' Convention on Climate (CCC) was launched by the French Government as a response tto the request for increased participation of citizens in democratic life. It gathered 150 people, randomly selected but representing the diversity of the French society on the basis of socio-demographic criteria: gender, age (from 16 to more than 80 ), education, place of residence (including overseas territories) and socio-professional category. The French Economic, Social and Environmental Council (ESEC) was in charge of overseeing the organisation of the event and of ensuring its independence, including that of the Governance Committee. ${ }^{1}$ The CCC mandate was to formulate a series of concrete measures aimed to achieve at least a 40\% reduction of greenhouse gas emissions by 2030 (compared to 1990) while preserving social justice. It is worth recalling that one of the main triggers for the yellow vest movement was the French version of the carbon tax initially planned in the 2019 Draft Budget which, if adopted, would have translated into an increase in fuel prices. It would thus have had a stronger financial impact on car-dependent working people and, as an indirect tax, it was deemed socially regressive as a heavier burden would be borne by people with lower incomes. The CCC activities spread over seven weekend sessions from October, 2019 to June, 2020. ${ }^{2}$ Citizens were split into five thematic working groups: "consuming”, "travelling", "housing”, “eating”, "producing and working”.

As for the democratic novelty of this experiment, the French President of the Republic committed to submit these measures, depending on their nature and characteristics, to a referendum, to a vote in Parliament or to direct implementation by the executive. The organisation of the CCC thus equates to the creation of a citizen's right of initiative, albeit an informal one, and represents as such a new exercise in participatory democracy mixing direct and indirect features.

\footnotetext{
${ }^{1}$ For the composition of the Governance Committee, see: https:// www.conventioncitoyennepourleclimat.fr/en/comite-gourvernance/.

${ }^{2}$ For more information on the CCC, see https://www.conventioncitoyennepourleclimat.fr/en/.
} 
Among the scientific community specialised in climate and ecological transition, some experts were enthusiastic over this experiment, whereas others were rather sceptical. The Sorbonne University Institute for Environmental Transition (SU-ITE) ${ }^{3}$ belonged to the first category. The Institute was created on the premises that (1) interdisciplinarity is necessary to develop comprehensive research strategies for climate and ecological transition, and that (2) participation from all segments of society (from citizens to private companies, political and administrative organisations) is a necessary requirement for ensuring their success. It embodies an approach based upon participative and integrative sciences, congruent with the CCC's own methodology. It is in this spirit that SU-ITE offered its expertise and support to the CCC and it is in this framework that I got the opportunity to observe and contribute to the CCC.

Essentially, I participated in the so-called «fact-checking » group of scientists. Our mission was to find factual responses to questions from the 150 citizens. We were never in direct contact with them, but received the questions of the various citizens' working groups through an internet network managed by specialists in citizen dialogue who were accompanying them in this exercise. It was clearly important to ensure that we could not interfere with the working groups discussions and debates in order to preserve the neutrality and the impartiality of the process. Nearly a hundred questions were asked, of a very diverse nature, addressing quantifications (e.g. compared greenhouse gas emissions from various car types) legal rules (e.g. does a law on agro-ecology exist?), but also a number of complex issues, for which no unique simple answer could be provided.

In addition to fact-checking, we had the opportunity to attend as observers, along with experts engaged in the analysis of the CCC process itself, ${ }^{4}$ the open sessions dedicated either to presentations and debates with experts and government representatives or to CCC general discussions.

It is based on this unique experience that I would like to make a few observations regarding what can be considered as some of the most promising features of this experiment for fostering participatory democracy and a more inclusive approach to science, whether at national or European level.

\section{Building effective consensus}

The citizens, gathered for the first time on 4 October, 2019, were asked about their motivation. Answers differed wildly, some of the participants even doubting the very existence of climate change issues. However, they all accepted the challenge. They auditioned experts on various topics from climate to economics and then built their own proposals. They were able to formulate concrete measures covering a wide field of application, from energy efficiency to mobility or agriculture, bearing in mind a social justice compass and constitutionality requirements.

It is worth noting that most of the resulting measures, prepared by each of the five working groups, were adopted by the assembly of the 150 citizens at a large majority. Only one proposal was rejected. This remarkable outcome shows that randomly selected people are able to collectively understand and capture the multi-faceted impact of climate change on society, what's more in a wide range of aspects. Moreover, the discussions showed a genuine concern for the common good, beyond individual specific interests, and the measures were proposed in this spirit. It is also worth acknowledging that they formed a coherent whole and in this regard fare much better than previous attempts to tackle environmental and climate transition through public debates.

\footnotetext{
3 See www.su-ite.fr.

${ }^{4}$ See: https://www.conventioncitoyennepourleclimat.fr/en/2020/01/20/the-citizens-conventionunder-the-researchers-microscopel.
} 
To some extent, this is a lesson also for scientists, who tend to stay within their discipline, making it difficult to build a systemic or holistic scientific perception and conception of a given problem. This is actually the very reason why our interdisciplinary Institute was created: as an attempt to decompartmentalise the study of critical issues and foster a multiplying effect in knowledge-building and problem-solving. Considering that the global challenges we are currently facing, such as environmental and climate transition, are multi-faceted phenomena which furthermore question not only our way of doing science but our societies and our way of life as citizens, this experiment can also be seen as a seed or a call for a more inclusive research methodology and output, combining lay and scientific expertise from multiple horizons.

\section{From technocracy to democracy: a bottom-up approach to expert knowledge}

Thus, 150 citizens, without any specific a priori knowledge regarding climate or ecology, were nevertheless able to address complex issues in these fields. On top of the previously mentioned fact-checking group of scientists at their disposal, citizens received information from experts who gave presentations. The speakers were suggested by the Governance Committee, but citizens also requested for some other speakers to be heard and rigorous debates between experts were organised as well.

This methodology gave rise to an interesting reversal of perspective. Instead of the usual dogmatic top-down approach: "experts teach people who listen", here people discussed with various experts in order to make their own mind and develop an informed position. As fact-checkers, we could witness their growing understanding of multi-disciplinary issues, through the increasing complexity and scope of the questions formulated by the thematic working groups.

On the one hand, this kind of exercise constitutes for us scientists, whether from humanities or natural sciences, an opportunity to avoid the tunnel vision trap, to question and refresh the way in which we are (too) used to look at an issue. On the other hand, it also shows, once again, how citizen science can produce efficient and quality outcomes.

Citizen science has strongly developed over the last twenty/thirty years. ${ }^{5}$ It can be summarised as scientific research conducted, in whole or in part by non-professional scientists. ${ }^{6}$ In natural sciences, in particular biodiversity or astronomy, and in humanities, citizen science has been practiced for centuries, leading to scientific discoveries as well as public education. Leonardo Da Vinci, Descartes, Leibniz, Newton, Herschel or Darwin are all famous examples of this tradition that needs revival in a contemporary fashion. In this regard, it is worth noting that it is one of the first times that citizen science finds a concrete application in drafting laws, as a parliament would. This opens new perspectives for democracy on the basis of new interaction channels between law-makers, professional experts and citizens. But apart from an invitation to rethink this triangular relationship, it confronts us with a triple helix where citizens play the part of both lay experts and lay law-makers in an attempt to create a meaningful connection between scientific questions and much needed societal changes. In this regard, some fruitful parallels can be drawn. Citizen science asks the question of how to integrate citizens in scientific research for the betterment of science and citizens' education. A democratic regime is faced with a similar and fundamental question: how to integrate citizens in the law-making process for the betterment of law and societies and for civic education? These are the kind of questions

\footnotetext{
5 See at EU level, SOCIENTIZE Project delivered to the European Commission's Digital Science Unit, DG CONNECT, 'Green paper on Citizen Science for Europe: Towards a society of empowered citizens and enhanced research' (2014); Soscientize, 'White paper on citizen science for Europe’ (2014).

${ }^{6}$ For an interesting matrix classifying the various initiatives in the field, see T. Schäfer and B. Kieslinger, 'Supporting emerging forms of citizen science: a plea for diversity, creativity and social innovation' (2016) 15 Journal of Science Communication 1.
} 
which seem sometimes to get lost in democracies entangled in their old and venerable ways and traditions, but which reappear acutely when faced with a crisis. At a time when democratic societies are jostled by global challenges, the rise of populism and disinformation, addressing these questions and finding truly common solutions become crucial. These are the questions that the organisation of a democratic experiment such as the CCC puts back on the front stage and aim to tackle in a concrete manner.

\section{An example for the Conference on the Future of Europe?}

It would be trite to say that the CCC process and results could not be improved. For example:

- Because of time constraints, the 150 citizens were dispatched within five thematic working groups without any window of opportunity for transverse discussions. It was therefore not possible to check the robustness of the proposed measures with respect to all objectives. The 150 citizens were aware of that. They did not only work during the week-end sessions, but also in between and asked for one extra session. Yet, more time would have certainly been beneficial to cross perspectives and findings and thus optimise outcomes.

- Fact-checking was too often fast-checking! Responses had to be sent quickly to allow the working groups to continue their debates. For some complex questions, we completed the answers after the relevant session had ended, to make citizens better informed when they would meet again. Here as well, more time would have been welcomed.

- Furthermore, our group of expert fact-checkers, initially composed of SU-ITE members and a few PhD researchers in political science, grew progressively, based on the nature of the questions received. More thoughts could be devoted to the composition of the fact-checking mission in order to constitute beforehand a source of (potential) experts from various backgrounds.

- Since it was the first time such experiment had been conducted and although care was taken to ensure that no bias would be introduced through the organisation process (experts, governance committee etc.), it would be important to assess whether this had really been the case. In this respect, the analyses and conclusions of the scientific observers regarding the functioning of the CCC will help improving the organisation of similar experiments in the future.

- Lastly, even the proposed measures would benefit from a more detailed and systemic analysis in order to possibly foster their positive impact and reduce potential negative effects.

Despite their perfectibility, the CCC proposals set up a consistent strategy for reducing the greenhouse gas emission at national level. Whether the pioneering Irish Citizens' Convention and Assemblies ${ }^{7}$ or the Climate Assembly UK, ${ }^{8}$ which started a few months after the French CCC, they all support the idea that there is a clear benefit in associating citizens to the devising of society evolution in response to major challenges. It is also worth noting that in its report, the participants in the CCC advocated for renewing the

\footnotetext{
7 The 2012-2014 Irish Convention on the Constitution led to the legal recognition of same-sex marriage in 2015, see https: / / www.citizensinformation.ie/en/government in ireland/ irish_constitution_1/citizens_assembly.html; the 2016-2017 Citizens' Assembly resulted in both overturning the abortion ban in 2018 and paving the way for the all-of-government 2019 Climate Action Plan; lastly there is an ongoing (2020) Citizens' Assembly on gender equality, see https:// www.citizensinformation.ie/en/government in ireland/irish constitution 1/ constitutional convention.html. On climate change more particularly, see L. Devaney, D. Torney, P. Brereton and M. Coleman, 'Deepening Public Engagement on Climate Change: Lessons from the Citizens' Assembly', (2020) Environmental Protection Agency Research Report, $\mathrm{n}^{\circ} 314$.
}

8 For more information, see its website: https://www.climateassembly.uk/about/. 
experiment and extending it to "fundamental French society topics". ${ }^{9}$ This seems to be the approach chosen for the Conference on the Future of Europe as well. Gathering citizens from all EU countries to work on important topics for Europe and Europeans could be a way to build a common vision, beyond the specific interests of each Member State, foster panEuropean solidarity, and contribute to the creation of a true European common good. The proposed two-year duration of the Conference offers time enough to implement a mechanism combining national-based and cross-country citizen panels, working on the various topics defined in collaboration with the relevant EU institutions.

Yet, some questions are still open: what kind of European participatory democratic experiment the Conference on the Future of Europe will be? Will it grant a real citizens' right of initiative in European law-making processes or represent the ultimate frontier of consultation? Which relationship will it set up between lay experts and professional experts? It is up to us, scientists from every alleys and citizens, to debate about the Conference's content and contours and, above all, to decide which contribution we would like to make in order to ensure its success.

What remains however is that the future of Europe does not have to be the affair of EU experts and professional politicians only, and can be drawn by citizens, experts in their own life in Europe. This could contribute to developing a feeling of belonging, citizens' awareness of their power to impact the course of the EU qua polity. Moreover, this would be an opportunity to develop European civic education while contributing to overcoming a perceived disconnection between the peoples of Europe and the European Union. If the CCC proved something it is that citizens' direct involvement in science and democracy might be one of the keys to meaningfully and thus successfully address their shortcomings.

Aknowledgments: I would like to thank Karine Caunes for her useful comments and our fruitful interdisciplinary exchanges.

Published in Eur Law J. 2020;1-5. https://doi. org/10.1111/eulj.12369

\footnotetext{
${ }^{9}$ Citizens' Convention on Climate report - Summary (2020), at 7 https: / / www.conventioncitoyennepourleclimat.fr/wp-content/uploads/2020/07/062020-CCC-propositionssynthese-EN.pdf.
} 